
\section{BMJ Quality}

\title{
Promoting the role of patients in improving hand hygiene compliance amongst health care workers
}

\author{
Maryam Ahmed Awaji, Khaled Al-Surimi
}

To cite: Ahmed Awaji M, Al-Surimi K. Promoting the role of patients in improving hand hygiene compliance amongst health care workers. BMJ Quality Improvement Reports 2016;5:u210787. w4336. doi:10.1136/ bmjquality.u210787.w4336

Received 2 January 2016 Revised 18 February 2016

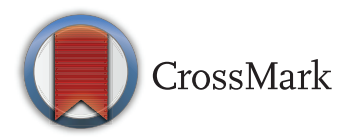

King Abdulaziz Medical City (KAMC), King Saud bin Abdulaziz University for Health Sciences, Riyadh, Kingdom of Saudi Arabia

Correspondence to Maryam Ahmed Awaji amalahmed.abha@hotmail. com

\section{ABSTRACT}

Hand hygiene is one of the fundamental measures necessary for reducing healthcare-associated infections. The adherence of health care workers to safe hand hygiene practices is low worldwide, despite evidence showing compliance with hand hygiene guidelines decreases infection rate. This project focuses on the role of patients in promoting healthcare workers' compliance with hand hygiene practices. Several plan-do-study-act (PDSA) cycles were conducted to test interventions which aimed to empower patients and increase staff members' adherence to hand hygiene practices. The initial findings presented on the run chart demonstrate that compliance among healthcare workers increased with the interventions; there was an increase of $15 \%$ compliance during the 10 days of project testing. We will need to collect more data to show continued and sustained improvement. Patients can play an important role in promoting safe care and hand hygiene practices.

\section{PROBLEM}

Hand hygiene compliance is considered a major quality performance indicator. The World Health Organization (WHO) recommends that the normal rate of hand hygiene compliance should be above $91 \%{ }^{1}$ Retrospective data showed that the hand hygiene compliance rate in our oncology department, in Saudi Arabia, was low. The overall estimate for hand hygiene compliance for the last quarter of 2014 was 30\%, and it was $22 \%$ for the first quarter of 2015 (See Figure 1, supplementary material). The central line associated bloodstream infection rate (CLABSI) per 1000 device-days for the last quarter of 2014 was 3.2 for temporary central lines and 2.7 for permanent lines. These values are above the normal standard rate of the National Healthcare Safety Network (NHSN) which is 2.0 for temporary central lines and 1.3 for permanent central lines. $^{2}$ The Center for Disease Control and Prevention (CDC) states clearly that hand hygiene is the most effective strategy in reducing transmission of infections in healthcare settings ${ }^{3}$. Thus, we decided to test change ideas to improve hand hygiene compliance as a method for reducing healthcare-associated infections.

\section{BACKGROUND}

The contamination of healthcare workers' hands can lead to the transmission of health-care-associated pathogens. ${ }^{4}$ Hence, one of the essential infection control measures for preventing health-care-associated infections is adherence to hand hygiene..$^{5}$ The global incidence rate of healthcare associated infections is estimated to range from 1.7 to 23.6 per 100 patients. The estimated economic burden directly linked to these types of infections is between $\$ 28.4$ to $\$ 33.8$ billion US dollars. ${ }^{7}$

Many studies have been undertaken to improve hand hygiene compliance using a variety of interventions such as staff education, ${ }^{8}$ more sinks $^{9}$ and the provision of alcohol gel. ${ }^{10}$ Another intervention which has been used is patient education and empowerment. ${ }^{11}$

Hand hygiene compliance is an important objective of the International Patient Safety Goals $(\text { IPSG })^{5}$ and is also one of the Joint Commission's International (JCI) standards and recommendations. The main aim of this project was to improve hand hygiene compliance among healthcare workers in an oncology unit in a hospital in Saudi Arabia.

\section{BASELINE MEASUREMENT}

We conducted a retrospective analysis of data from the infection prevention and control department. Hand hygiene compliance amongst healthcare workers for the last quarter of 2014 was $30 \%$ and for the first quarter of 2015 was 22\% (See Figure 1, supplementary material). 
DESIGN

The quality improvement team used a brainstorming technique and fish-bone diagram to identify the root causes of non-compliance with hand hygiene. We also developed a 'Hand Hygiene Compliance Process Flow Chart' which showed when patients can ask about the hand hygiene (see Figure 2, supplementary material). We used the model for improvement to test several interventions which included:

- Educating patients about the importance of hand hygiene and encouraging them to ask their healthcare workers about hand hygiene practice.

- Using reminders for health workers about hand hygiene.

We developed an action plan and measured the impact of these interventions by calculating the hand hygiene compliance rate, using the hand hygiene observation form developed by World Health Organization. The WHO form measures hand hygiene compliance $(\%)$ as actions/opportunities x $100^{12}$

\section{STRATEGY}

These interventions were tested over a 10 day period, using PDSA cycles. A total of 50 staff members work on the oncology unit and each day hand hygiene compliance was tested for 20-30 staff members.

PDSA Cycle 1: We carried out a pilot test by educating two patients about hand hygiene. We found initially that the patients were hesitant to ask staff about handwashing before the physical examination. They were worried this might have a negative impact upon the health service provided. The hand hygiene compliance rate increased from $5 \%$ at baseline to $10 \%$ over the first 3 days. As result of PDSA cycle 1, we adapted this idea and decided to add the patient educator to the patient daily education sessions.

PDSA Cycle 2: Thirteen patient educators ran daily education sessions for patients about the importance of hand hygiene. They ran group sessions and provided leaflets about hand hygiene in English and Arabic in the patients' rooms. The compliance rate started to increase and reached $18 \%$. We decided to include the infection prevention and control practitioner as part of the daily education sessions.

PDSA Cycle 3: Fourteen infection control practitioners became part of the daily education sessions. In this cycle we started educating and training more patients about the importance of hand hygiene. We showed them posters and illustrative materials about importance of hand hygiene practice using the 5 hand-washing movements. We also discussed the same issue with staff during staff meetings. The hand hygiene compliance rate continued to increase up to $20 \%$.

\section{RESULTS}

This project demonstrated that educating and empowering patients can have a positive impact on the hand hygiene
Daily Hand Hygiene Compliance Rates

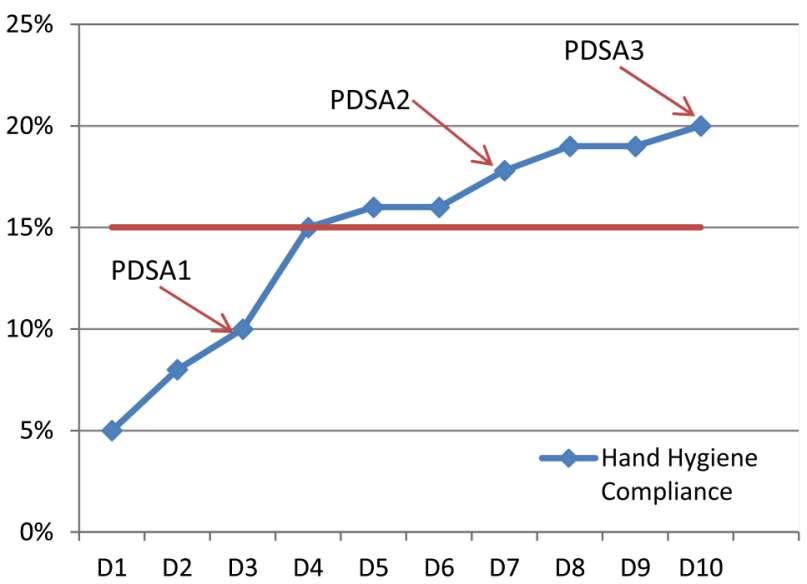

Figure 1 Results

compliance of staff members. The run chart (see Figure 1) shows clear steady increase from a baseline of $5 \%$ up to $20 \%$ over the project period (10 consecutive days).

\section{LESSONS AND LIMITATIONS}

We learned several lessons from this quality improvement project. Engaging patients in healthcare can help to improve outcomes. The idea of providing daily education sessions and increasing patient awareness of hand hygiene practices played an important role in improving hand hygiene practice.

One of the limitations is that we tested these interventions over a short time period (10 days) and so we would need to collect more data going forwards. We focused on hand hygiene compliance and did not assess the quality of the hand washing process itself. We did not assess whether our interventions impacted upon the quarterly hand hygiene compliance rates or rates of central line infection; this should be addressed going forwards. We hope to make this a permanent strategy to promote hand hygiene practice hospital-wide.

\section{CONCLUSION}

Patients can play a key role in promoting safe hand hygiene practices amongst healthcare workers. The findings from this project are consistent with previous studies. ${ }^{6}$ It would have been useful to use different innovative tools including videos and other interactive media. The hand hygiene observation form should be used regularly, as part of this strategy, to assess the hand hygiene compliance. Although this improvement project has shown some initial promising results, continous monitoring is required to ensure that compliance continues to improve and is sustained.

Acknowledgements Dr. Aiman Ramadan, Advisor of Health Surveillance in Infection Control Department.

Mr. Yahya Bakhit, Infection Control Practitioner.

Ms. Hadeel Al Dirihm, Quality Specialist.

Declaration of interests Nothing to declare. 
Ethical approval There was no need for ethical approval for this quality improvement project. We intended to implement the idea of empowering patients to ask about the hand hygiene compliance. This is in line with our hospital policy on improvement projects aiming to improve hand hygiene. The hospital is $\mathrm{JCl}$ accredited and is very committed to improving patient safety.

Open Access This is an open-access article distributed under the terms of the Creative Commons Attribution Non-commercial License, which permits use, distribution, and reproduction in any medium, provided the original work is properly cited, the use is non commercial and is otherwise in compliance with the license. See:

- http://creativecommons.org/licenses/by-nc/2.0/

- http://creativecommons.org/licenses/by-nc/2.0/legalcode

\section{REFERENCES}

1. Pittet D, Allegranzi B, Boyce J. The World Health Organization guidelines on hand hygiene in health care and their consensus recommendations. Infection Control \& Hospital Epidemiology. 2009;30:611-22.

2. Scheithauer S, Häfner H, Schröder J, Koch A, Krizanovic V, Nowicki $\mathrm{K}$, et al. Simultaneous placement of multiple central lines increases central line-associated bloodstream infection rates. American journal of infection control. 2013:41:113-7.

3. Larson EL, Quiros D, Lin SX. Dissemination of the CDC's Hand Hygiene Guideline and impact on infection rates. American journal of infection control. 2007;35:666-75.
4. Jarvis WR. Selected aspects of the socioeconomic impact of nosocomial infections: morbidity, mortality, cost, and prevention. Infection Control. 1996;17:552-7.

5. Soule BM, Memish ZA, Malani PN. Best practices in infection prevention and control: an international perspective: Joint Commission Resources; 2012.

6. World Health Organisation. WHO Guidelines on Hand Hygiene in Health Care: a Summary. 2009

7. Shekelle PG, Wachter RM, Pronovost PJ, Schoelles K, McDonald K, Dy $\mathrm{S}$, et al. Making health care safer II:an updated critical analysis of the evidence for patient safety practices. Evidence report/technology assessment. 2013(211):1-945.

8. Allegranzi B, Sax H, Bengaly L, Riebet H, Minta DK, Chraiti M-N, et al. Successful implementation of the World Health Organization hand hygiene improvement strategy in a referral hospital in Mali, Africa. Infection Control \& Hospital Epidemiology. 2010;31:133-41.

9. Lankford MG, Zembower TR, Trick WE, Hacek DM, Noskin GA, Peterson LR. Influence of role models and hospital design on hand hygiene of health-care workers. Emerging infectious diseases. 2003:9:217-23.

10. Hugonnet S, Perneger TV, Pittet D. Alcohol-based handrub improves compliance with hand hygiene in intensive care units. Archives of Internal Medicine. 2002;162:1037-43.

11. McGuckin M, Storr J, Longtin Y, Allegranzi B, Pittet D. Patient empowerment and multimodal hand hygiene promotion: a win-win strategy. American Journal of Medical Quality. 2011;26:10-7.

12. World Health Organization, Hand Hygiene observation form www. who.int/gpsc/5may/Observation_Form.doc. 
Erratum: Promoting the role of patients in improving hand hygiene compliance amongst health care workers

Ahmed Awaji M, Al-Surimi K. Promoting the role of patients in improving hand hygiene compliance amongst health care workers BMJ Quality Improvement Reports 2016;5:u210787.w4336. doi:10.1136/bmjquality.u210787.w4336. Since this report was first published online the author affiliation has been updated so Cameroon has been removed from the address.

Open Access This is an open-access article distributed under the terms of the Creative Commons Attribution Non-commercial License, which permits use, distribution, and reproduction in any medium, provided the original work is properly cited, the use is non commercial and is otherwise in compliance with the license. See:

- http://creativecommons.org/licenses/by-nc/2.0/

- http://creativecommons.org/licenses/by-nc/2.0/legalcode

BMJ Quality Improvement Reports 2016;5:u210787.w4336corr1. doi:10.1136/bmjquality.u210787.w4336corr1 